\title{
Bilateral Homonymous Hemianopia with Sparing of Central Vision After Subdural Hematoma
}

\author{
Marco Soza, Patricio Tagle, Trevor Kirkham and Jaime Court
}

\begin{abstract}
A patient with bilateral homonymous hemianopia with preservation of the central vision, spatial disorientation and memory deficits secondary to bilateral occipital and mesial temporal infarctions, is presented. The cerebral damage followed a subdural hematoma with tentorial herniation and compression of both posterior cerebral arteries.
\end{abstract}

\begin{abstract}
RÉSUMÉ: Hémianopsie homonyme bilatérale épargnant la vision centrale à la suite d'un hématome sous-dural Nous rapportons le cas d'un patient présentant une hémianopsie homonyme bilatérale avec préservation de la vision centrale, désorientation spaciale et déficit de la mémoire secondaires à des infarcissements occipitaux et mésiotemporaux bilatéraux. Les dommages cérébraux sont survenus à la suite d'un hématome sous-dural avec hernie tentorielle et compression des deux artères cérébrales postérieures.
\end{abstract}

Can. J. Neurol. Sci. 1987; 14:153-155

Bilateral homonymous hemianopia from cerebral infarction is a rare occurrence. ${ }^{1,2}$ Most reported patients present with a visual field defect that is partial and recovers spontaneously. ${ }^{1,3}$ In some cases there is concomitant optic atrophy ${ }^{4}$ which makes it difficult to interpret the visual field defects; in others, the presence of occipital infarction has not been sufficiently documented either by computerized tomography or by postmortem examination of the brain. The most common causes appear to be occlusions of the posterior cerebral arteries secondary to atheroma, emboli or migraine. ${ }^{3.5}$ Bilateral homonymous hemianopia with sparing of central vision is even less frequent. ${ }^{1.5,6}$

In autopsy material, tentorial herniation of the hippocampal gyrus of the temporal lobe has been clearly correlated with occipital infarction, due to compression of the posterior cerebral arteries. ${ }^{7}$ However, clinical reports of bilateral homonymous hemianopia with sparing of the central vision after tentorial herniation are rare..$^{4,7,8}$

In this paper, we present the case of a patient who developed a permanent and complete bilateral homonymous hemianopia with preservation of central vision after transtentorial herniation secondary to subdural hematoma. In addition, he developed severe anterograde and retrograde amnesia and spatial disorientation. Computerized tomography of the brain revealed bilateral occipital infarctions.

\section{Case RePort}

A 38 year old, previously healthy man presented with progressive headache, nausea and blurring of vision. Two months prior to admission, he had suffered a head injury which had left him unconscious for approximately two hours. Examination revealed bilateral papilledema, spatial disorientation and amnesia; he was unable to recall any of the events of the past two months. There were no signs of focal neurologic deficits, and the general physical examination was unremarkable. Twenty hours after his admission, the patient developed convulsive seizures involving his right extremities and a persistent right hemiparesis. The pupils became dilated, the right more than the left, and both were unresponsive to light. Babinski sign was present bilaterally. An EEC showed bursts of bilateral and synchronous delta waves over both frontal lobes. Blood pressure was $170 / 110$, pulse $80 / \mathrm{min}$. and regular. A right carotid angiogram, through femoral catheterization, showed a large right frontal subdural hematoma and bilateral tentorial herniation.

After surgical evacuation of the hematoma, the hemiparesis, pupillary abnormalities and papilledema rapidly resolved, but a severe defect in the visual fields was noted, consisting of bilateral homonymous hemianopia with sparing of the central $10^{\circ}$ of vision in both eyes (Figure 1). The patient behaved as if he were blind, but he could recognize a small pin on the floor.

The spatial disorientation persisted and despite having spent many days in hospital, the patient never learned to go from his room to the bathroom. Furthermore, while in his room, he was unable to find his own bed. When offered a chair, he sat with the chair back to his side or even in front of him. On several occasions, the patient tended to sit beside the chair. Often we observed him trying to get into bed from the foot of the bed instead of from the side near the pillows.

From the Department of Neurology and Neurosurgery of Catholic University of Chile, Santiago (Drs. Soza. Tagle, Court) and from McGill University. Montreal, Quebec (Dr. Kirkham)

Received December 10, 1985. Accepted in final form January 19, 1987

Reprint requests to: Dr. Marco Soza, Departamento de Neurologia, Hospital Universidad Catolica, Marcoleta 347. Santiago, Chile 


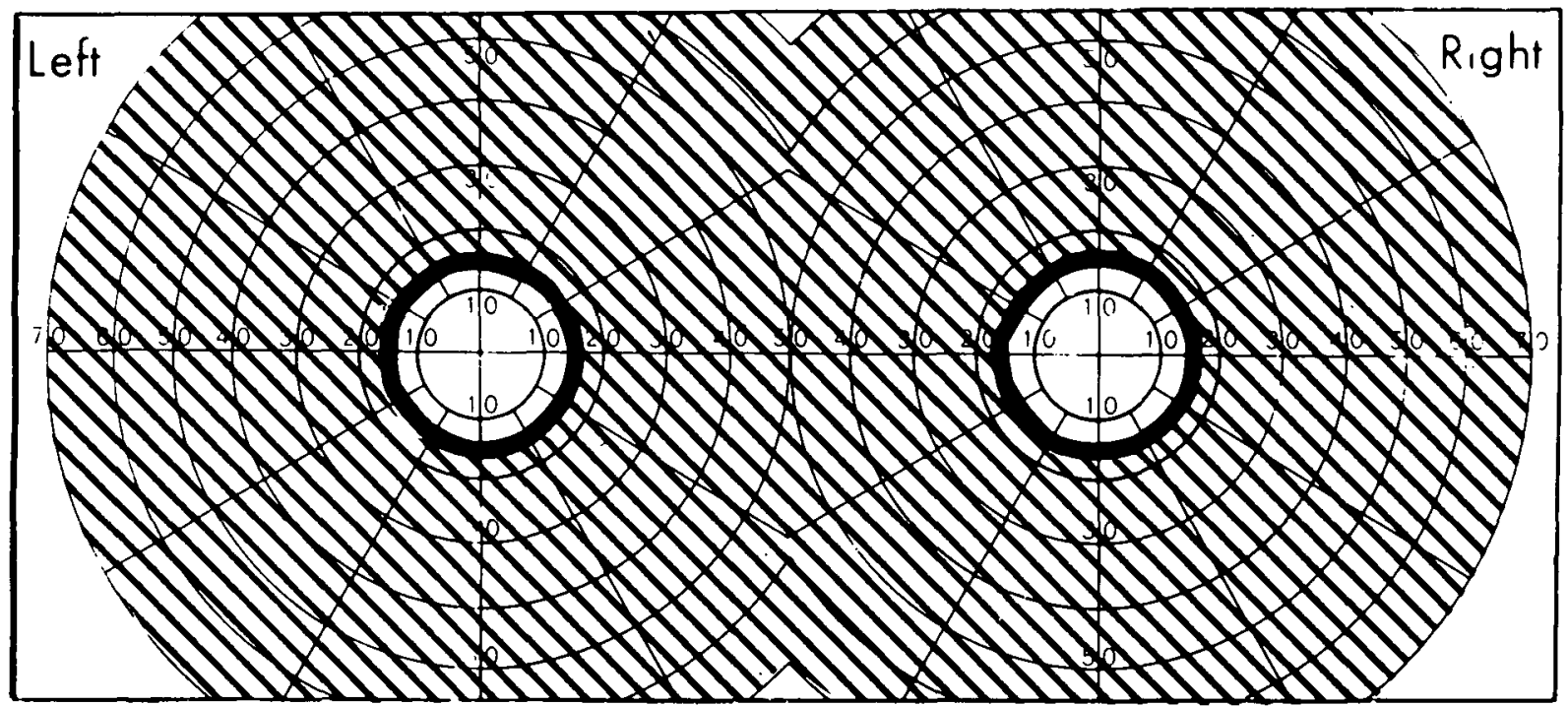

Figure I - Visualfields showing bilateral homonymous hemianopia with preservation of central vision in both eyes.

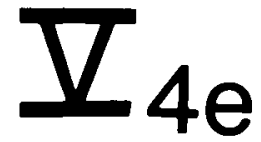

The third remarkable deficit was a complete loss of memory for recent events. Despite the fact that he was able to recall the first and middle names of his thirteen brothers and sisters, and to give many details of his marriage ten years ago, he could not remember that he had been examined just 30 minutes previously.

These severe neurologic deficits remained essentially unchanged during a four year follow-up period. The visual fields of both eyes remained constricted although visual acuity was $20 / 20$ bilaterally. No pupillary abnormalities, oculomotor deficits, alexia or visual agnosia were encountered. The fundi were normal, as well as optokinetic nystagmus. A formal psychometric study revealed severe impairment both in spatial orientation and in memory for recent events, with relative preservation of intellectual functions.

Two years postoperatively, a computerized tomography of the brain showed bilateral occipital infarctions, as well as slight dilation of the left Sylvian cistern consistent with discrete atrophy of the left temporal lobe (Figure 2A, 2B).

\section{Discussion}

In the case presented here, a right subdural hematoma caused bilateral tentorial herniation as documented by the signs of midbrain dysfunction and by carotid angiography. As the hippocampal gyrus herniates through the tentorial incisura, it presses the ipsilateral posterior cerebral artery against the tentorial edge. The contralateral posterior cerebral artery can also be pulled against the tentorial edge by the downward displacement of the brainstem. ${ }^{4}$ The obvious result of bilateral posterior cerebral artery occlusion is bilateral occipital infarction, as well as damage in the basomesial surface of both temporal lobes. These lesions were confirmed in our patient by computerized tomography.

The cerebral insult suffered by our patient resulted in a remarkable clinical picture consisting of bilateral homonymous hemianopia with sparing of the central vision, spatial disorientation and amnesia. These changes remained almost unaltered after more than four years of follow-up.

The bilateral homonymous hemianopia in the case reported here is of special interest because of its completeness, which has been seldom reported, ${ }^{9}$ and because of the full preservation of central vision with normal visual acuity in the 10-20 degrees in the center of the fields of both eyes. The sparing of central vision in posterior cerebral artery occlusions is due to the fact that the occipital pole derives its blood supply from terminal branches of the middle cerebral artery. ${ }^{1,3}$ It is worth noting as well that our patient did not develop optic atrophy (as in many cases in the literature $)^{4}$ indicating that no major damage to the pre-geniculate visual pathways occurred. The preservation of optokinetic nystagmus is also in agreement with an occipital origin of the visual field defects.

Symonds and MacKenzie ${ }^{1}$ found that among 58 cases with bilateral homonymous hemianopia collected from the literature and from their own experience, they encountered only 11 with circular sparing of central vision. In their cases in which postmortem confirmation of bilateral occipital infarction was available, arterial thrombosis or emboli were identified as the cause. McAuley and Ross-Russell ${ }^{5}$ encountered only one case with preservation of central vision among 39 subjects with visual defects secondary to vascular lesions of the posterior visual pathways. Their cases were correlated with CAT scans. Nepple et $\mathrm{al}^{2}$ reported three patients who after subdural hematomas developed extensive visual defects with relative sparing of central vision. However, the only visual field shown in their paper is a combination of a right homonymous hemianopia with a left quandrantanopia.

Bilateral occlusion of the posterior cerebral arteries may produce severe amnesia, ${ }^{10}$ as in our case. In these circumstances, the critical area for memory impairment seems to be the subcortical temporal white matter or temporal stem. ${ }^{10}$ In our patient, in addition to bilateral occipital infarctions, the CT scan showed evidence of atrophy at least of the left temporal lobe.

Another remarkable deficit in our patient was his spatial disorientation. It is rarely encountered in the literature as a consequence of posterior cerebral artery occlusions. ${ }^{1}$ It has been described in bilateral parieto-occipital lesions. ${ }^{11}$ Nevertheless, in our patient, we can not rule out that the spatial disorientation might have been due to direct right parietal lobe compression and damage by the subdural hematoma itself. Other signs occasionally reported in patients with occipital infarctions such a visual agnosia, alexia, or denial of the visual deficit, were not present in the case reported here. 


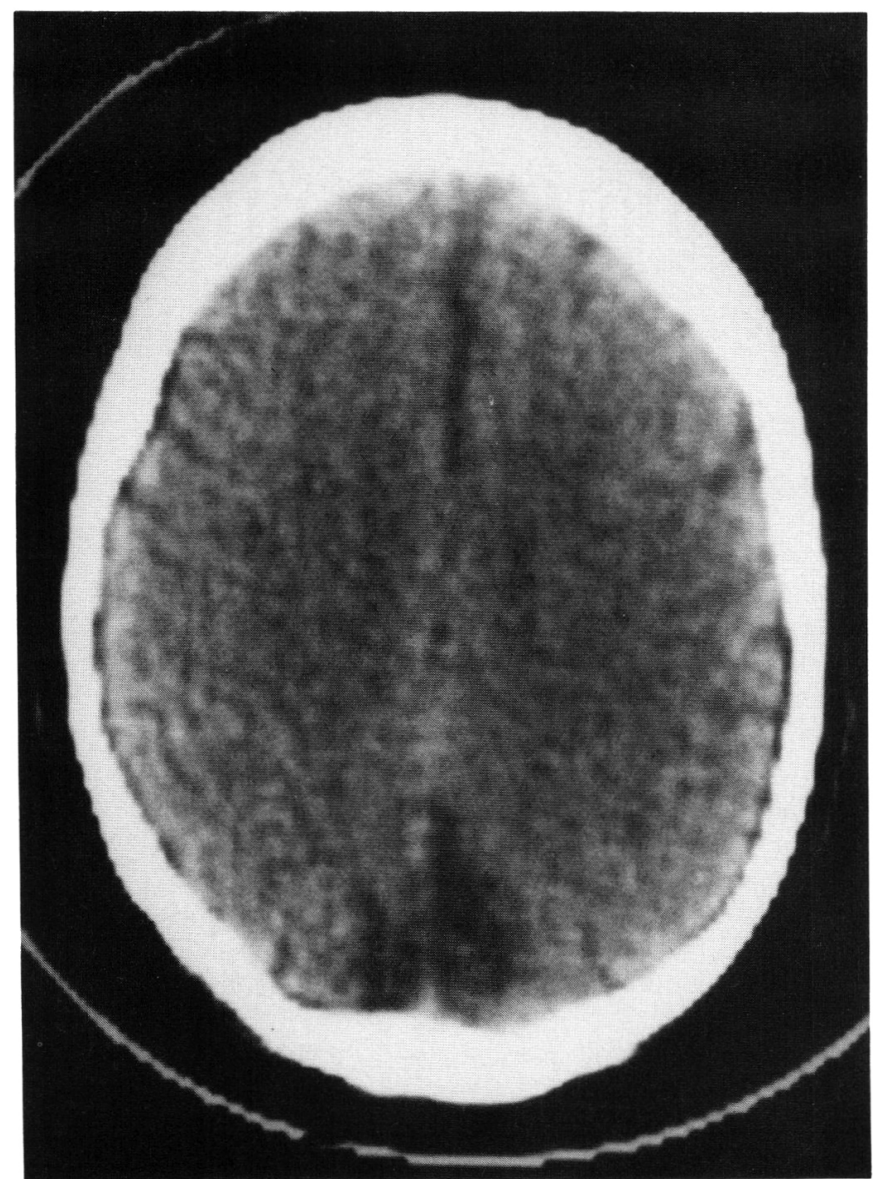

A

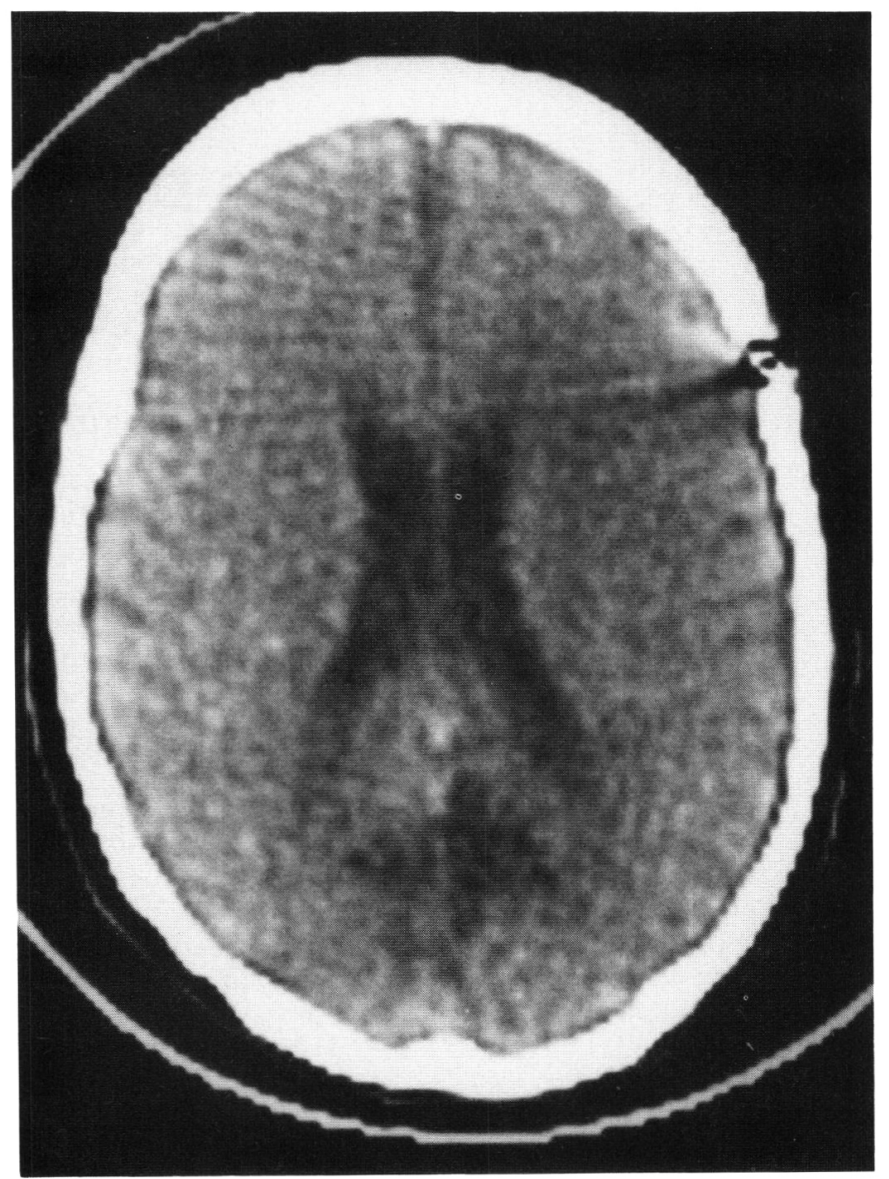

B

Figure $2-A) C T$ scan showing bilateral occipital infarctions. B)CT scan at a lower level than Figure $2 A$ showing anatomical preservation of both occipital poles.

\section{ACKNOWLEDGEMENTS}

This work was supported by the Gildemeister Foundation. The authors express their thanks to Drs. S. Carpenter and G. Karpati for reviewing the manuscript and to Mrs. M. Erdelyi for secretarial assistance.

\section{REFERENCES}

1. Symonds C, MacKenzie I. Loss of vision from cerebral infarctions. Brain 1957; 80: 415-455.

2. Nepple EW, Appen RE, Sackett JT. Bilateral homonymous hemianopsia. Am J Opthalmol 1978; 86: 536-543.

3. Kaul SN, Du Boulay GH, Kendall BE, et al. Relationship between visual field defect and arterial occlusion in the posterior circulation. J Neurol Neurosurg Psychiatr 1974; 37: 1022-1030.
4. Keane JR. Blindness following tentorial herniation. Ann Neurol 1980; 8: 186-190.

5. McAuley DL and Ross-Russel RW. Correlation of CAT scan and visual field defects in vascular lesions of the posterior visual pathways. J Neurol Neurosurg Psychiatr 1979; 42: 298-311.

6. Walsh FB, Hoyt WF. The Visual Sensory System in Clinical Neuro-ophthalmology. The Williams \& Wilkins Company, Baltimore, 1969; I: 60-67.

7. Hoyt WF. Vascular lesions of the visual cortex with brain herniation through the tentorial incisura. Arch Ophthalmol 1960; 64: 44-57.

8. Matwijecky C, Steinbok P. Hemianopsia. A presenting feature of acute epidural hematomas. Neurosurgery 1982; 11:247-249.

9. Frontera AT. Bilateral homonymous hemianopsia with preservation of central vision. Mt Sinai J Med NY 1974; $41: 480$.

10. Horel JA. The neuroanatomy of amnesia. Brain 1978; 101: 403-446.

11. Kase CS, Troncoso JF, Court JE, et al. Global spatial disorientation. J Neurol Sci 1977; 34: 267-278. 